\title{
Multilevel approaches to increase fruit and vegetable intake in low-income housing communities: final results of the 'Live Well, Viva Bien' cluster-randomized trial
}

Kim M. Gans ${ }^{1,2,3,4^{*}}$ D, Patricia Markham Risica ${ }^{3,4}$, Akilah Dulin Keita ${ }^{3,4}$, Laura Dionne ${ }^{3}$, Jennifer Mello3, Kristen Cooksey Stowers ${ }^{2,5}$, George Papandonatos ${ }^{6}$, Shannon Whittaker ${ }^{7}$ and Gemma Gorham ${ }^{1}$

\begin{abstract}
Background: Fruit and vegetable (F\&V) intake can reduce risks for chronic disease, but is much lower than recommended amounts in most Western populations, especially for those with low income levels. Rigorous research is needed on practical, cost-effective interventions that address environmental as well as personal determinants of $F \& V$ intake. This paper presents the results of a cluster randomized controlled trial evaluating the efficacy of 'Live Well, Viva Bien' (LWVB), a multicomponent intervention that included discount, mobile fresh F\&V markets in conjunction with nutrition education.

Methods: Fifteen subsidized housing sites in Providence County, Rhode Island (8 intervention and 7 control sites) were randomized using a random number generator. Of these, nine housed elderly and/or disabled residents and six housed families. A total of 1597 adult housing site residents (treatment $n=837$; control $n=760$ ) were enrolled (73\% women, 54\% Hispanic, 17\% black, Mean age 54 years). A year-long multicomponent intervention including mobile F\&V markets plus nutrition education (e.g. campaigns, DVDs, newsletters, recipes, and chef demonstrations) was implemented at intervention sites. Physical activity and stress interventions were implemented at control sites. Follow-up occurred at 6 and 12 months. The main outcome measure was F\&V consumption measured by National Cancer Institute's 'Eating at America's Table All Day Screener'.

Results: From baseline to 12 months, the intervention group increased total F\&V intake by 0.44 cups with the control group decreasing intake by 0.08 cups $(p<.02)$. Results also showed an increased frequency of F\&V eating behaviors compared to the control group $(p<.01)$. There was a clear dose response effect of the F\&V markets with participants who reported attending all or most of the markets increasing F\&V intake by 2.1 cups and 0.86 cups, respectively compared with less than half cup increases for lower levels of market attendance $(p<.05)$. Use of the DVDs, recipes and taste-testings was also associated with greater increases in F\&V intake; however, use of other educational components was not.

(Continued on next page)
\end{abstract}

\footnotetext{
*Correspondence: kim.gans@uconn.edu

1 Department of Human Development and Family Studies, University of Connecticut, Storrs, USA

${ }^{2}$ University of Connecticut Intitute for Collaboration in Health, Interventions

and Policy, Storrs, USA

Full list of author information is available at the end of the article
}

(c) The Author(s). 2018 Open Access This article is distributed under the terms of the Creative Commons Attribution 4.0 International License (http://creativecommons.org/licenses/by/4.0/), which permits unrestricted use, distribution, and reproduction in any medium, provided you give appropriate credit to the original author(s) and the source, provide a link to the Creative Commons license, and indicate if changes were made. The Creative Commons Public Domain Dedication waiver (http://creativecommons.org/publicdomain/zero/1.0/) applies to the data made available in this article, unless otherwise stated. 
(Continued from previous page)

Conclusions: LWVB is the first cluster, randomized controlled trial to demonstrate the efficacy of year-round F\&V markets on improving F\&V intake for low-income adults, which provides an evidence-base to bolster the mission of mobile produce markets. Further, the results more broadly support investment in environmental changes to alleviate disparities in F\&V consumption and diet-related health inequities.

Trial registration number: Clinicatrials.gov registration number: NCT02669472

Keywords: Diet, Nutrition, food access, Fruit and vegetable, Farmer's market, Mobile market, Nutrition education, housing, community, food environment

\section{Background}

Fruit and vegetable (F\&V) intake can promote health, prevent obesity, and lower risks for hypertension, coronary heart disease, stroke, type 2 diabetes, some cancers and all-cause mortality [1-6].A comparative risk assessment of the global burden of disease identified diets low in $F \& V$ to be one of the five leading risk factors worldwide [7]. Despite potential benefits, F\&V consumption is much lower than recommended amounts in most Western populations [8]. Although dietary recommendations vary among countries, most are in line with the World Health Organization's recommendation to consume a daily minimum of $400 \mathrm{~g}$ of $\mathrm{F} \& \mathrm{~V}$, or the equivalent of five servings of F\&V per day [9]. In the United States [10, 11], 37.7 and $22.6 \%$ of U.S. adults report consuming F\&V less than once per day; only $18 \%$ meet the dietary guidelines for fruits and only 13\% meet guidelines for vegetables [12]. Groups at greater risk for low F\&V consumption include those of low-income or low educational status [12]. These socioeconomic status (SES) disparities in F\&V consumption are partly attributable to the food environment in low-income neighborhoods, where residents often have limited access to affordable, healthful food [13]. Two of the most common reported barriers to F\&V consumption are, in fact, high cost and limited access $[14,15]$.

Farmer's markets and mobile F\&V markets have emerged as innovative and promising approaches for increasing access to healthful food [16]. Although such markets demonstrate potential for improving dietary intake, there have been no randomized trials studying their efficacy to date. Moreover, as Dibsdall, et al. found, access and affordability are only two of the factors contributing to low F\&V consumption for low SES adults; personal determinants need to be addressed as well [17]. The most common personal factors are hectic lifestyles (leaving little time for shopping and cooking), taste preferences, negative attitudes and perceived norms regarding healthy eating, and lack of knowledge, skills, self-efficacy and social support [18]. Thus, research is needed on practical, cost-effective interventions that not only improve F\&V access and affordability, but also address these barriers. Also, the majority of studies to date have focused mainly on individual level barriers to F\&V consumption rather than on environmental level barriers. The purpose of this paper is to present the final results of the 'Live Well, Viva Bien' (LWVB) trial, which was designed to fill these research gaps by addressing both personal and environmental determinants to increase F\&V consumption for low-income populations. Results from the current study can inform the development of local partnerships (e.g, between produce markets and hospitals or public housing agencies) [19], institutional policies (e.g., at the food-bank level) as well as public policies shaping access to federal food assistance aiming to improve access to $F \& V$ among low-income populations and other marginalized populations.

\section{Methods \\ Overview}

'Live Well, Viva Bien' (LWVB) was a cluster, randomized controlled trial designed to evaluate the efficacy of a multicomponent intervention that included discount, mobile fresh F\&V markets in conjunction with a nutrition education intervention [20]. All study activities occurred at 15 subsidized housing complexes in Providence County, Rhode Island with 8 sites receiving the $F \& V$ intervention and 7 sites receiving a comparison intervention. Pre-intervention focus groups were conducted with housing complex residents (from non-study sites) to inform intervention development. Adult residents from each housing site were recruited for the evaluation cohort prior to site randomization. The multicomponent intervention lasted 1 year and included baseline, 6-month and 12 -month evaluation surveys as well as extensive quantitative and qualitative process evaluation throughout the course of the study. Participants were given a $\$ 30$ gift card incentive upon completion of each of the three surveys (\$90 total). All study protocols were approved by the Brown University Institutional Review Board and all participants provided informed consent. Details of the intervention components and trial protocols are presented elsewhere [20]. 


\section{Recruitment of housing sites}

The Providence, Pawtucket and Woonsocket Housing Authorities assisted with the selection and recruitment of the subsidized housing complexes that participated in the study. To be eligible, the housing complex needed to have: at least 190 units; a relatively low turnover rate $(<20 \%)$; a community room or center; a willingness to be randomized into one of the two experimental conditions, and support for the study activities for the duration of the study. In addition, at least $90 \%$ of the residents needed to be able to speak and read either English or Spanish. Housing site pairs were matched by number of units, type of site (family or elderly/disabled) and race/ethnicity of residents. Of the 15 sites ultimately recruited, 9 were elderly/ disabled sites and 6 were family sites. A Resident Assistant was hired from each participating site to assist with recruitment and intervention activities.

\section{Participant recruitment}

Though intervention activities were open to all housing complex residents approximately 100 residents per site were recruited to participate in an evaluation cohort. Recruitment began with an onsite, recruitment event prior to which posters were displayed throughout the housing complex and informational hangers were placed on each apartment door. Research staff also knocked on apartment doors to invite residents to participate. Interested residents then met with bilingual Brown research staff in the community room of the housing complex where they were screened for eligibility. To participate in the evaluation cohort, residents needed to: be 18 years of age or older; be full-time residents of the housing complex; shop for their household's food at least half of the time; not have any major medical conditions that would prevent them from participating in study activities or events; not be planning to move in the next year; be able to read and understand either English or Spanish; and have access to a Digital Video Disk (DVD) player (or computer that could play DVDs).

\section{Baseline surveys and randomization}

Baseline surveys were then conducted with eligible participants either in person or via computer-assisted telephone interviews. After the baseline surveys were completed at each pair of sites, the project data manager randomly assigned the sites to either the intervention or control group using a random number generating function in Excel. The study enrolled a total of 7 sites in the control group and 8 sites in the intervention group, which included one pilot site. If housing residents were ineligible or did not choose to be in the evaluation cohort, they were still invited to participate in the intervention activities. As randomization was at the site level, participants were not blinded to the intervention condition; however, Brown evaluation staff were blinded to the group assignment of the sites.

\section{Intervention \\ Formative research}

Ten focus groups (eight exploratory and two confirmatory) were conducted with 79 low-income, racially and ethnically diverse residents at three, non-participating housing sites to inform the development of recruitment, intervention and evaluation materials [20].

\section{Intervention framework}

The multicomponent LWVB intervention was based on a social ecological model, which recognizes that behavior is affected by multiple levels of influence and that an intervention will be most effective when it targets changes in multiple levels or domains [21-23]. The multi-level LWVB intervention operated within the intrapersonal/individual, interpersonal (social), and environmental domains. The theoretical framework for the LWVB intervention was the Social Cognitive Theory (SCT), which defines behavior as a triadic, dynamic, and reciprocal interaction of personal factors, behavior and the environment [24-26]. See the Logic Model in Fig. 1 and previous work for further details about how theory informed the intervention [20].

\section{Intervention components}

The 12-month intervention featured discount, fresh F\&V markets called 'Fresh to You' (FTY), as well as a multicomponent, educational intervention. F\&V prices were set each day by the market coordinator, who attempted to keep the prices at or below the retail prices at local supermarkets by looking at online grocery store produce prices. The intervention began with a highlypublicized 'Kick-Off' event, during which we brought the first FTY market to each intervention site, along with chef-run cooking demonstrations/taste-testing events, recipes and detailed information about upcoming intervention activities. Regularly scheduled, discount, fresh F\&V markets continued to be held at each intervention site for a one-year period [20, 27]. Between 50 and 70 different, local and non-local produce items (including staples, seasonal items, culturally-desired ethnic produce and exotic produce) were sold at the markets at or below retail (supermarket) prices. The types of F\&V sold at the market were informed by the pre-study focus groups as well as by customer comments and requests throughout the study. These requests were forwarded to the market coordinator, who then made sure those products were available at future markets at that site. The markets lasted 2 hours and were always held indoors at the senior and disabled housing complexes and during inclement weather at family housing complexes. In good weather, the markets were held 


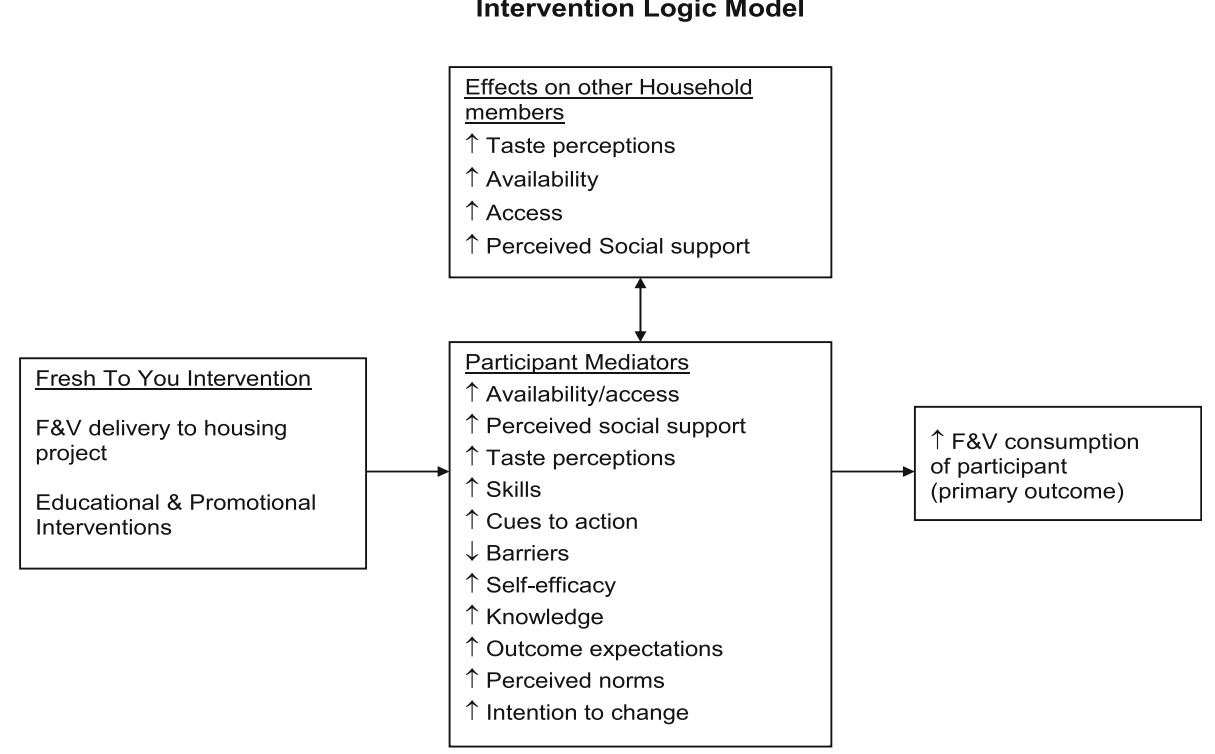

Fig. 1 Intervention Logic model of the Live Well/Niva Bien study

outdoors at the family housing complexes in a car trailer that had been retrofitted to serve as a mobile market [20]. We originally planned to bring weekly markets to each intervention site. However, limited resident participation in the markets during the third and fourth weeks of the month led us to reduce the frequency of the markets to the first 2 weeks of each month. It became clear early in the study that residents were much more likely to shop soon after receiving their monthly Supplemental Nutrition Assistance Program (SNAP) benefits on the 1st of each month.

Before the first market was held, an educational/informational packet was delivered to all intervention housing complex residents that included a large, reusable FTY shopping bag containing a binder that included an overview of the intervention, the first month's newsletter, three educational DVDs, 48 recipe cards and three-hole binder sleeves to store the remaining newsletters they would receive over the course of the intervention. All materials were provided in English or Spanish. A brief description of each motivational/ educational intervention component follows. See Gans et al. [20] for more detail.

The intervention included 2 six-week educational/motivational campaigns. The first campaign ('Just Add 2') began soon after the baseline surveys were completed and was designed to increase participants' daily F\&V consumption by two servings. The second campaign ('Color Your Plate') focused on increasing the variety of F\&V that participants ate and began soon after the 6-month evaluation surveys were completed. Both campaigns included full-color booklets with goal-setting activities, educational and motivational content, and F\&V trackers. A midpoint and final event were held at each intervention site that included chef-led cooking demonstrations, taste-testing events and raffles with prizes.

Three, 20-min DVDs and 48 corresponding recipe cards were developed and distributed to all intervention housing complex residents to support and encourage increased F\&V intake. The DVDs included FTY market information; cooking demonstrations; success stories and descriptions of health benefits associated with F\&V. Each month, a two-page, full-color newsletter was delivered to the door of each intervention housing complex resident. The newsletters highlighted the produce in season that month, its key nutrients, health benefits along with recipes and information regarding how to choose, prepare, store and save time and money purchasing and preparing F\&V. Six times during the year, a chef presented cooking demonstrations and taste-testing events at each intervention housing complex and provided attendees with corresponding English/Spanish recipe cards.

\section{Comparison/control intervention}

Two, six-week, non-nutritional, educational and motivational campaigns were provided to residents of the 7 comparison group housing complexes. The 'Take 10!' Campaign aimed to increase residents' daily physical activity by $10 \mathrm{~min}$ per day. The 'Stress Less' Campaign aimed to help participants reduce stress by adding stress-reduction activities into their daily routines. These comparison group campaigns included the same types of information and activities as the intervention group campaigns as well as raffles with prizes. Campaign 
participants also received a free, 6-week membership to the YMCA.

\section{Process evaluation}

Detailed FTY market sales data (e.g. total sales, \# of shoppers, items purchased and tender types) were captured by the FTY markets' point-of-sale cashiering system. Brown research staff recorded the number of residents who participated in the campaigns and other intervention-related activities. The 6- and 12-month follow-up surveys also included process evaluation questions regarding participation in and perceptions of each component of the intervention as well as open-ended questions regarding what participants liked/disliked about the program, what they learned from the program, and how the program could be improved. A subset of raw responses to the open-ended questions was reviewed by the investigators and research staff, who then created coding categories for the responses. Two staff members independently coded the responses into themes and met regularly with the data manager to decide how to handle responses that were coded differently. Additional coding categories were added as new themes emerged.

\section{Effect evaluation}

Baseline, mid-term and 12-month follow-up surveys were conducted by Brown research staff, either in-person at the housing complex, or by phone via computer-assisted telephone interviewing. All data that were collected in person were first reviewed for completeness and then entered into the online computer database. Baseline surveys began in June 2011 for the pilot site and ended in August 2013 for the last pair of sites; 12-month follow-up surveys were completed for the last pair of sites in October 2014.

\section{Outcome measures}

The study's primary outcome was F\&V intake measured using the 18 item National Cancer Institute (NCI) 'Eating at America's Table All Day Screener'. [28] The Screener queries 18 F\&V consumed over the past month. Participants were asked to report the frequency (from never to 5 or more times per day) of F\&V they ate last month and serving size (from less than $1 / 2$ cup to more than $1 \frac{1 / 2}{2}$ cups) for each F\&V group in the survey. Response options were standardized to a daily cup serving and then total $F \& V$ consumption was calculated by summing the products of each F\&V group. The responses to the frequency questions were recoded to daily averages based on standard NCI methods [28]. Screener data was recoded to examine changes in intake of fruits omitting juice, vegetables omitting French fries, and F\&V together omitting juice and French fries.
Additionally, F\&V practices were assessed in a series of eleven questions adapted from previous food habits questionnaires [29-31]. These questions included how often in the past few months participants: ate fruit at breakfast; added vegetables to breakfast dishes; ate more than one type of fruit per day; ate more than one type of vegetable per day; ate a lettuce-based salad or vegetable at lunch; ate fruit at lunch; ate a lettuce-based salad or vegetable at dinner; ate two or more different vegetables or a vegetable and a salad at dinner; added vegetables to other foods or dishes; ate a fruit or vegetable as a snack in-between meals; and ate just fruit as dessert instead of a rich dessert. Each question had five levels of response (always, often, sometimes, rarely or never). Responses were scored so that higher scores were indicative of higher F\&V intake behaviors and then the sum of all scores was calculated as the total Fruit and Vegetable Habits Questionnaire (FVHQ) score.

\section{Demographic measures}

Demographic variables were categorized as follows: age (18-39, 40-59, 60+); gender (male vs. female); marital status (single, married, divorced, separated, widowed, other); race (White, Black or African American, mixed race, or other); birth country (United States vs other), years lived in US $(0-5,6-10,11-15,16-19,20+)$; Hispanic (yes/no); Hispanic culture (Dominican, Puerto Rican, and other, which included Columbian, Guatemalan, Mexican, Cape Verdean, among other groups); country of origin (US, other country); language(s) spoken at home (English only, Spanish only, Both, more English than Spanish, Both equal amounts of time, Both more Spanish than English, or Other language); employment status (full time, part time, unemployed, disabled, retired, student/homemaker); education (First to 9th grade, Grades 10-12, Vocational/Technical School or Some college; BA Degree/Post graduate); household income (Less than $\$ 6000, \$ 6000-\$ 11,999, \$ 12,000$ $\$ 17,999, \$ 18,000+)$; number of adults and children living in household [1-9]; and participation in food assistance programs (Any of the following programs: WIC, SNAP (Food Stamps), Emergency Food Program, Summer Food Service Program, Senior Citizen Meal Program, Meals on Wheels Program) (yes/no). At the site level, we also looked at type of housing site (elderly/disabled vs. family).

\section{Data analysis}

To compare demographic characteristics by experimental group (control v. intervention), chi square tests were used for categorical variables and analysis of variance was used for continuous variables. To examine changes in F\&V intake, linear mixed effects models (SAS PROC MIXED) were generated. The model included fixed 
effects for time and random intercepts for housing site and participants nested within the housing sites, and does not require imputation for missing data assuming that data are missing-at-random (MAR) [32]. Robust standard errors were used in order to correct for heteroscedasticity. Site level intra-class correlation was calculated for residents of the same site across time, as well as between residents of the same site. See Appendix. Because it was possible for participants to move from one site to another during the study, we asked residents and omitted data from those that changed sites. Month 6 follow-up data was omitted for participants $(n=17)$ who moved anywhere outside of their original housing site before exposure to 4 months of intervention (and they were excluded from the month 12 evaluation). Month 12 follow-up data was omitted for participants $(n=7)$ who moved anywhere outside of their original housing site before exposure to 8 months of intervention.

Dose variable distributions were explored. Given the broad distribution of participation, market participation was assessed including all response levels (all, most, some, few, none). For recipe use, the response of, "none," was collapsed with the response, "I didn't get recipes." Variables for newsletter reading was collapsed at the middle category comparing those who read at least half of the newsletter compared with less than half of the newsletter. Lower use compelled collapsing variables for DVD watching, participation in Taste Tests and Campaigns to watching or participation in one or more with watching or participation in none of the DVD/taste tests/campaigns. T-tests for each outcome of fruit, vegetable or F\&V consumption were assessed by each dose variable. All analyses were performed using SAS version 9.4 (SAS Institute, Cary, NC).

\section{Results}

A total of 1597 housing complex residents were enrolled in the evaluation cohort (Fig. 2), which represents $88 \%$ of those who initially registered. Just over half (56\%) of the participants were recruited from elderly/disabled housing complexes and $44 \%$ were recruited from family housing complexes. A total of 837 participants were enrolled at the intervention sites and 760 at the control sites. Follow-up evaluation was conducted with 695 intervention group participants (83\%) and 659 comparison group participants $(87 \%)$ at 6 months $(p<.05)$ and with 653 intervention group participants (78\%) and 621 comparison group participants $(82 \%)$ at 12 months $(p<.06)$.

Participants enrolled (Table 1) were mostly women (73\%) with a mean age of 54 years. The largest marital status category was single (43\%); only $14 \%$ were married. Less than half (48\%) of participants identified their race as White; $17 \%$ as Black, $20 \%$ as Mixed Race and smaller percentages of other racial groups. The majority of participants were Hispanic (54\%) of which $45 \%$ were Dominican and $44 \%$ Puerto Rican, with an additional $11 \%$ from other cultural groups. Of those not born in the US, which comprised about half of the study sample, $46 \%$ reported having been in the country more than 20 years. Regarding language, $41 \%$ spoke only English at

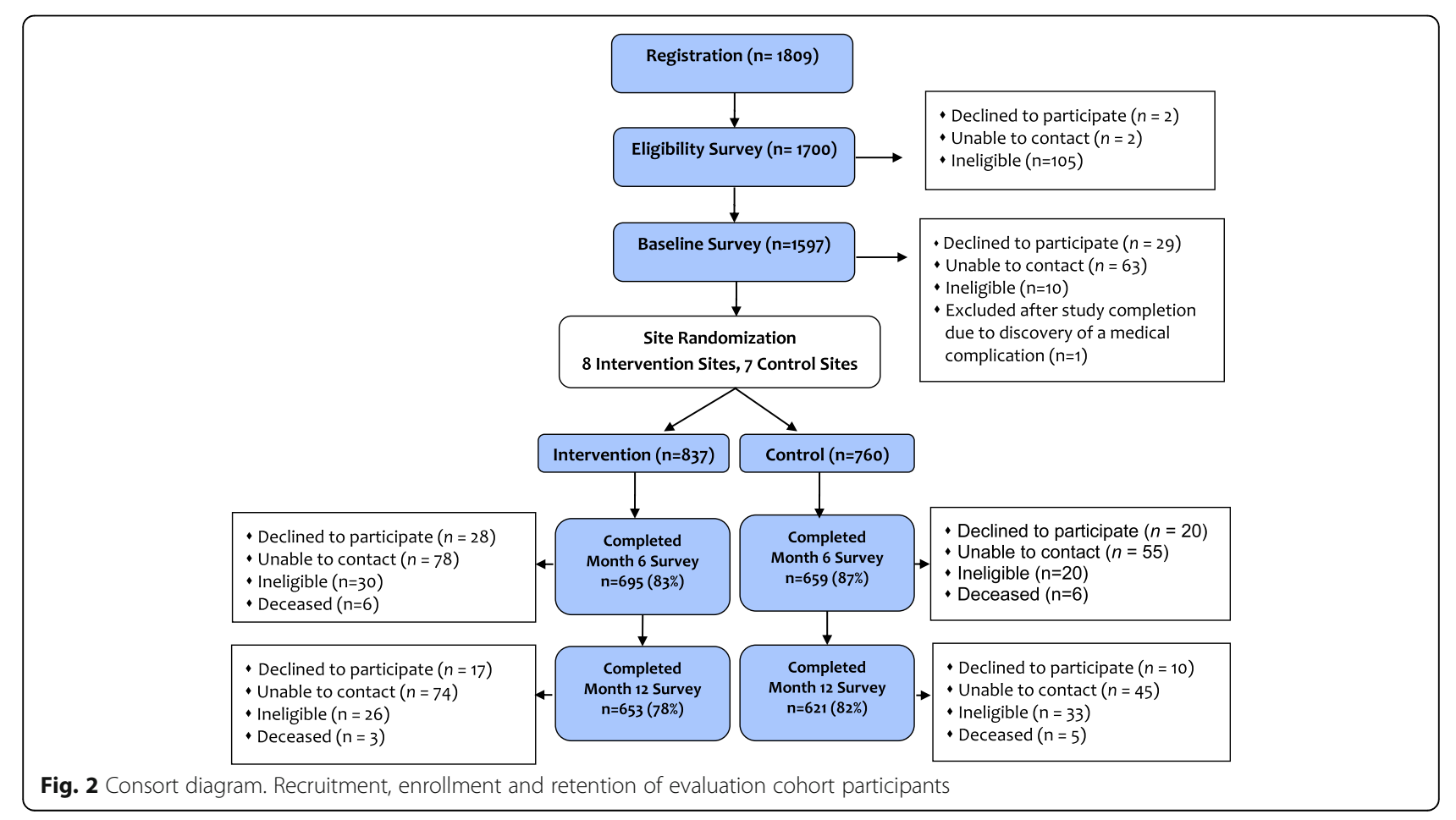


Table 1 Demographics of Study Sample Consisting of Adults aged 18+, by Experimental Group ( $N=1597)$

\begin{tabular}{|c|c|c|c|c|c|}
\hline Variable & Category & All \% (n) & Intervention \% (n) & Control \% (n) & $p$-value \\
\hline \multirow[t]{2}{*}{ Site } & Elderly & 56.5 (903) & $57.2(479)$ & $55.8(424)$ & 0.56 \\
\hline & Family & $43.5(694)$ & $42.8(358)$ & $44.2(336)$ & \\
\hline \multirow[t]{2}{*}{ Gender } & Male & $26.6(425)$ & $25.7(215)$ & $27.6(210)$ & 0.38 \\
\hline & Female & $73.4(1172)$ & $74.3(622)$ & $72.4(550)$ & \\
\hline \multirow[t]{3}{*}{ Age category } & $18-39$ & 24.5 (392) & $24.1(202)$ & 25 (190) & $0.01^{*}$ \\
\hline & $40-59$ & $33.5(535)$ & $36.7(307)$ & $30(228)$ & \\
\hline & $60+$ & $42(670)$ & $39.2(328)$ & $45(342)$ & \\
\hline Mean age & & $53.7(1597)$ & $53.5(837)$ & $53.9(760)$ & 0.68 \\
\hline \multirow[t]{6}{*}{ Marital status } & Single & $42.9(683)$ & $45.6(380)$ & $40(303)$ & 0.07 \\
\hline & Married & $14.4(229)$ & $15.1(126)$ & $13.6(103)$ & \\
\hline & Divorced & $17.7(281)$ & $16.6(138)$ & $18.9(143)$ & \\
\hline & Separated & $10.2(162)$ & $9.1(76)$ & $11.3(86)$ & \\
\hline & Widowed & $13.3(211)$ & $12.5(104)$ & $14.1(107)$ & \\
\hline & Other, please describe & $1.6(25)$ & $1.1(9)$ & $2.1(16)$ & \\
\hline \multirow[t]{4}{*}{ Race } & White & $48(715)$ & 49.5 (383) & $46.2(332)$ & 0.24 \\
\hline & Black & $17.3(258)$ & $18.1(140)$ & $16.4(118)$ & \\
\hline & Mixed & $19.5(291)$ & $18.4(142)$ & $20.8(149)$ & \\
\hline & Other & $15.2(227)$ & $14(108)$ & $16.6(119)$ & \\
\hline \multirow[t]{2}{*}{ Hispanic } & Yes & $53.9(857)$ & $55.2(460)$ & $52.4(397)$ & 0.26 \\
\hline & No & $46.1(734)$ & $44.8(373)$ & $47.6(361)$ & \\
\hline \multirow[t]{3}{*}{ Hispanic Culture } & Dominican & 44.5 (379) & $44.2(202)$ & $44.8(177)$ & 0.25 \\
\hline & Puerto Rican & $44.4(378)$ & $46.2(211)$ & $42.3(167)$ & \\
\hline & Other & $11.2(95)$ & $9.6(44)$ & $12.9(51)$ & \\
\hline \multirow[t]{2}{*}{ What country were you born in } & United States & $50.2(799)$ & $49(410)$ & $51.4(389)$ & 0.35 \\
\hline & Other Country & $49.8(794)$ & $51(426)$ & $48.6(368)$ & \\
\hline \multirow[t]{5}{*}{ How many years have you lived in the US } & $0-5$ Years & $11.7(93)$ & $11.3(48)$ & $12.1(45)$ & 0.99 \\
\hline & 6-10 Years & $14.4(115)$ & $14.6(62)$ & $14.3(53)$ & \\
\hline & $11-15$ Years & $14.4(115)$ & $14.1(60)$ & $14.8(55)$ & \\
\hline & 16-19 Years & $13.3(106)$ & $13.2(56)$ & $13.5(50)$ & \\
\hline & 20 Years or more & $46.1(367)$ & 46.8 (199) & $45.3(168)$ & \\
\hline \multirow[t]{6}{*}{ What languages are spoken in your home } & English only & $41.1(657)$ & $40.4(338)$ & $42(319)$ & 0.37 \\
\hline & Spanish only & $19(303)$ & $19.1(160)$ & $18.8(143)$ & \\
\hline & Both, more English than Spanish & $9.6(153)$ & $9(75)$ & $10.3(78)$ & \\
\hline & Both, equal amounts of time & $8(127)$ & $8.8(74)$ & $7(53)$ & \\
\hline & Both, more Spanish than English & $15.5(248)$ & $16.6(139)$ & 14.3 (109) & \\
\hline & Other language, please describe & $6.8(109)$ & $6.1(51)$ & $7.6(58)$ & \\
\hline \multirow[t]{6}{*}{ Employment Status } & Full time & $5.2(83)$ & $5.5(46)$ & $4.9(37)$ & 0.08 \\
\hline & Part time & $10.4(165)$ & $8.6(72)$ & $12.3(93)$ & \\
\hline & Unemployed & $21.4(341)$ & $21.4(179)$ & $21.4(162)$ & \\
\hline & Disabled & $33.1(527)$ & $35.2(294)$ & $30.8(233)$ & \\
\hline & Retired & $20.6(327)$ & $19.3(161)$ & $22(166)$ & \\
\hline & Student/Homemaker & $9.3(148)$ & $9.9(83)$ & $8.6(65)$ & \\
\hline
\end{tabular}


Table 1 Demographics of Study Sample Consisting of Adults aged 18+, by Experimental Group ( $N=1597)$ (Continued)

\begin{tabular}{|c|c|c|c|c|c|}
\hline Variable & Category & All \% (n) & Intervention \% (n) & Control \% (n) & $p$-value \\
\hline \multirow[t]{4}{*}{ Education } & First - 9th grade & $34.9(554)$ & $35.2(293)$ & $34.6(261)$ & \multirow[t]{4}{*}{0.99} \\
\hline & Grades 10-12 & $45.7(725)$ & $45.7(380)$ & $45.8(345)$ & \\
\hline & Vocational/Tech/Some college & $15.3(243)$ & $15(125)$ & $15.6(118)$ & \\
\hline & BA degree/Post grad & $4(64)$ & $4.1(34)$ & $4(30)$ & \\
\hline \multirow[t]{4}{*}{ Household Income } & $<\$ 6000 / y r$ & $16.3(230)$ & $15.3(114)$ & $17.3(116)$ & \multirow[t]{4}{*}{0.60} \\
\hline & $\$ 6000$ to $\$ 11,999 / \mathrm{yr}$ & $51.6(730)$ & $53.2(395)$ & 49.9 (335) & \\
\hline & $\$ 12,000$ to $\$ 17,999 / \mathrm{yr}$ & $21(297)$ & $20.3(151)$ & $21.8(146)$ & \\
\hline & $\$ 18,000+$ & $11.1(157)$ & $11.2(83)$ & $11(74)$ & \\
\hline \multirow{9}{*}{$\begin{array}{l}\text { Number of adults and children living } \\
\text { in household }\end{array}$} & 1 & $54.6(871)$ & $52.2(436)$ & $57.2(435)$ & \multirow[t]{9}{*}{$0.008^{*}$} \\
\hline & 2 & $17.1(273)$ & $18.2(152)$ & $15.9(121)$ & \\
\hline & 3 & $12.3(197)$ & $12.2(102)$ & $12.5(95)$ & \\
\hline & 4 & $8.8(141)$ & $10.3(86)$ & $7.2(55)$ & \\
\hline & 5 & $4.5(72)$ & $5.3(44)$ & $3.7(28)$ & \\
\hline & 6 & $1.7(27)$ & $0.8(7)$ & $2.6(20)$ & \\
\hline & 7 & $0.4(7)$ & $0.6(5)$ & $0.3(2)$ & \\
\hline & 8 & $0.4(6)$ & $0.2(2)$ & $0.5(4)$ & \\
\hline & 9 & $0.1(2)$ & $0.2(2)$ & $0(0)$ & \\
\hline \multirow{2}{*}{$\begin{array}{l}\text { Food Assistance (Any of the following: } \\
\text { WIC, SNAP (Food Stamps), Emergency } \\
\text { Food Program, Summer Food Service } \\
\text { Program, Senior Citizen Meal Program, } \\
\text { Meals on Wheels) }\end{array}$} & Yes & 82 (1305) & 84.1 (702) & 79.8 (603) & \multirow[t]{2}{*}{$0.03^{*}$} \\
\hline & No & 18 (286) & 15.9 (133) & $20.2(153)$ & \\
\hline
\end{tabular}

*indicates statistical significance $(p<0.05)$

home, with $19 \%$ speaking only Spanish and 33\% speaking both languages. The largest group of participants (33\%) reported their employment status as "disabled," while $21 \%$ reported that they were unemployed; $21 \%$ retired, and only $15 \%$ working full or part time. In terms of education, $35 \%$ said they had less than a 10th grade education; $46 \%$ had a 10th -12 th grade education and only $4 \%$ earned a college degree. Most participants (68\%) reported a household income of less than $\$ 12,000$ per year including $16 \%$ who reported less than $\$ 6000$ per year. More than half (55\%) reported living alone.

The experimental groups were balanced at baseline on most demographic characteristics. However, the intervention group had slightly more participants in some of the younger age groups compared with the control group $(p<.01)$; though the mean age was not different between groups. Also, the intervention group had slightly fewer participants living alone (52\%) compared with the control group $(57 \%, p<.01)$.

Process evaluation data indicated that over the course of the year-long intervention, an average of 23 markets were held at each site with a smaller average number of markets at the family sites (21.3 markets) than at the elderly sites (23.8 markets). Elderly sites also had a higher average number of customers and sales per market (average of 29 customers and \$245 in sales) compared with the family sites (average of 9 customers and $\$ 82$ in sales). For elderly sites, more of the sales were paid for with cash (43\%) than with SNAP (37\%), while at the family sites, the opposite was true (cash $33 \%$, SNAP $50 \%$ ). Less than $20 \%$ of participants used debit or credit cards. The top five selling F\&V were bananas, cucumbers, red grapes, navel oranges and strawberries for the elderly sites and strawberries, bananas, navel oranges, red grapes and cilantro for the family sites.

At the 12-month survey (Table 2), more than half of the evaluation cohort participants $(57 \%)$ reported that they had attended a few of the FTY markets; $18.6 \%$ attended some of the markets; while only $7.7 \%$ attended all or most of the markets; and $16.6 \%$ reported that they had not attended any of the markets. About half of the participants reported that FTY market prices $(47 \%)$ and F\&V quality (51\%) was about the same as at local grocery stores; while 33\% reported that the FTY prices and F\&V quality (48\%) was better than at grocery stores. The majority (74\%) rated the FTY market F\&V quality as very good or excellent and the $F \& V$ prices as very good or excellent $(53 \%)$. The large majority $(80 \%)$ of participants reported that the FTY markets always or often 
Table 2 Intervention Group Evaluation Cohort Participant Self-Reported F\&V Market participation and Satisfaction at 12 months $(N=653)$

Frequency Percent

\begin{tabular}{lcc}
\hline Would you say you shopped at...? & 108 & 16.6 \\
None of the markets & 373 & 57.2 \\
A few of the markets & 121 & 18.6 \\
Some of the markets & 26 & 4.0 \\
Most of the markets & 24 & 3.7 \\
All of the markets & 176 & 32.6 \\
Would you say the prices of the FV sold at the Fresh To You markets were...? \\
Lower than grocery store prices & 251 & 46.5 \\
About the same as grocery store prices & 113 & 20.9 \\
Higher than grocery store prices & 7 & 1.3 \\
How would you rate the cost of the FV sold at the Fresh To You markets? \\
Poor & 50 & 9.2 \\
Not so good & 201 & 37.0 \\
Good & 148 & 27.3 \\
Very good & 137 & 25.2
\end{tabular}

Would you say the quality of the FV sold at the Fresh To You markets was...?

Worse than what is sold at grocery stores $\quad 8 \quad 1.5$

About the same as what is sold at grocery $\quad 277 \quad 50.8$

stores

$277 \quad 50.8$

Better than what is sold at grocery stores $\quad 260 \quad 47.7$

How would you rate the quality of FV sold at the Fresh To You markets?

$\begin{array}{lll}\text { Poor } & 2 & 0.4 \\ \text { Not so good } & 15 & 2.8 \\ \text { Good } & 122 & 22.4 \\ \text { Very good } & 174 & 31.9 \\ \text { Excellent } & 232 & 42.6\end{array}$

How often did the Fresh To You markets sell the types of FV that you like to eat?

$\begin{array}{lll}\text { Always } & 289 & 53.1 \\ \text { Often } & 146 & 26.8 \\ \text { Sometimes } & 91 & 16.7 \\ \text { Rarely } & 15 & 2.8 \\ \text { Never } & 3 & 0.6\end{array}$

Did anyone else in your household ever shop at the Fresh To You markets?

$\begin{array}{lll}\text { Yes } & 178 & 35.3\end{array}$

$\begin{array}{lll}\text { No } & 327 & 64.8\end{array}$

sold the F\&V that they liked and that they purchased about the same amount of F\&V at the FTY markets as they did at grocery stores. Most participants (65\%) reported that no one else in their household shopped at the markets.
Educational campaigns were provided to intervention and control groups with varied success. Table 3 details the self-reported participation of evaluation cohort participants in the various educational activities. A lower proportion of evaluation cohort participants in the comparison group reported attending the "Take 10" physical activity campaign (25\%) and "Stress Less" campaigns (20\%) compared with participants in the intervention group evaluation cohort who reported attending the "Just Add 2," (46\%) and, "Color Your Plate," (38\%) F\&V campaigns. Of those who did not join campaigns, the highest reason reported by both groups was not hearing about the campaign (data not shown). Of those who did participate, about $75 \%$ of respondents reported that the campaigns were very helpful.

Participation in other intervention components was also mixed. For recipes, $27 \%$ of intervention group cohort participants reported using all or most of the recipes, while $47 \%$ reported using some and $21 \%$ reported using none of the recipes. Of the 12 monthly newsletters, $62 \%$ reported reading 6 or fewer of the newsletters, but the majority of those that did read them found them very (69\%) or somewhat (20\%) helpful. For the DVDs, $48 \%$ watched at least one DVD, and those who did watch them, found them to be very $(75 \%)$ or somewhat $(14 \%)$ helpful. For the taste-testing events, 35\% reported attending at least one event with $31 \%$ reporting that these events affected their purchasing a lot and $14 \%$ reporting that they affected their purchasing some. One-third of participants reported that others in their household used the LWVB intervention materials.

Mixed models (Table 4) examining the effect of time overall showed that there were significant changes in $\mathrm{F} \& \mathrm{~V}$ intake over time favoring the intervention group, $(p<.02)$. From baseline to 12 months, the intervention group increased total $\mathrm{F} \& \mathrm{~V}$ intake by 0.44 cups with the control group decreasing intake by 0.08 cups. An increase in the frequency of $\mathrm{F} \& \mathrm{~V}$ eating behaviors was also observed as demonstrated by increases in the F\&V Habits Questionnaire score over time, with the intervention group increasing by 0.24 and the control group increasing by 0.14 from baseline to 12 months $(p<.01)$.

While the study was not originally powered to look at F\&V changes by housing site type, we decided to examine the study results within elderly/disabled and housing sites because study staff noticed differences in enthusiasm for the intervention by site type. Table 5 shows the F\&V changes for the elderly housing sites and family sites separately. Mixed models examining the effect of time overall showed that there were significant changes in $\mathrm{F} \& \mathrm{~V}$ intake over time favoring the intervention group, $(p<.008)$ in the elderly sites. From baseline to 12 months, the intervention group increased total F\&V 
Table 3 Self-reported Participation of evaluation cohort participants in the educational intervention components. (6 Months N=1354, 12 Months $N=1275$ )

\begin{tabular}{|c|c|c|c|c|c|c|c|c|}
\hline \multicolumn{9}{|l|}{ Campaign } \\
\hline & \multicolumn{4}{|l|}{ Control } & \multicolumn{4}{|l|}{ Intervention } \\
\hline & \multicolumn{2}{|l|}{6 Months } & \multicolumn{2}{|l|}{12 Months } & \multicolumn{2}{|l|}{6 Months } & \multicolumn{2}{|l|}{12 Months } \\
\hline & \multicolumn{2}{|l|}{ Take 10} & \multicolumn{2}{|l|}{ Stress Less } & \multicolumn{2}{|l|}{ Just Add 2} & \multicolumn{2}{|c|}{ Color Your Plate } \\
\hline & Frequency & $\%$ & Frequency & $\%$ & Frequency & $\%$ & Frequency & $\%$ \\
\hline \multicolumn{9}{|c|}{ Did you join the campaign? } \\
\hline Yes & 159 & 24.6 & 122 & 19.9 & 317 & 46.5 & 244 & 38.1 \\
\hline No & 487 & 75.4 & 491 & 80.1 & 365 & 53.5 & 396 & 61.9 \\
\hline \multicolumn{9}{|c|}{ How helpful was the campaign? } \\
\hline Very helpful & 121 & 76.6 & 98 & 81.0 & 230 & 72.6 & 190 & 78.2 \\
\hline Somewhat helpful & 11 & 7.0 & 10 & 8.3 & 40 & 12.6 & 32 & 13.2 \\
\hline A little helpful & 22 & 13.9 & 12 & 9.9 & 40 & 12.6 & 17 & 7.0 \\
\hline Not at all helpful & 4 & 2.5 & 1 & 0.8 & 7 & 2.2 & 4 & 1.7 \\
\hline
\end{tabular}

Other Intervention Components for the Intervention Group Only.

6 Months
Frequency Percent

12 Months

Frequency

Percent

How many of the recipes that you received in your LWVB binder did you try?

$\begin{array}{lllll}\text { All of them } & 54 & 7.9 & 70 & 10.8 \\ \text { Most of them } & 106 & 15.5 & 105 & 16.2 \\ \text { Some of them } & 323 & 47.2 & 306 & 47.1 \\ \text { None of them } & 158 & 23.1 & 135 & 20.8 \\ \text { I didn't get any recipes } & 43 & 6.3 & 34 & 5.2\end{array}$

How many of the monthly newsletters did you read?

$\begin{array}{lll}\text { I didn't get any newsletters } & 0 & 0 \\ \text { None of them } & 0 & 0 \\ 1 & 59 & 9.0 \\ 2 & 103 & 15.7 \\ 3 & 87 & 13.3 \\ 4 & 58 & 8.8 \\ 5 & 39 & 6.0 \\ 6 & 138 & 21.0 \\ 7 & 75 & 11.4 \\ 8 & 97 & 14.8 \\ 9 & & \\ 10 & & \\ 11 & & \\ 12 & & \end{array}$

$70 \quad 11.2$

$63-10.1$

$35-5.6$

$92 \quad 14.7$

$77-12.3$

$65-10.4$

$54 \quad 8.7$

$33-5.3$

$11-1.8$

$13-2.1$

$5 \quad 0.8$

$28 \quad 4.49$

20.3

$\begin{array}{ll}76 & 12.2\end{array}$

How helpful were the newsletters that you did read?

$\begin{array}{lllll}\text { Very helpful } & 319 & 66.2 & 340 & 69.3 \\ \text { Somewhat helpful } & 105 & 21.8 & 96 & 19.6 \\ \text { A little helpful } & 49 & 10.2 & 46 & 9.4 \\ \text { Not at all helpful } & 9 & 1.9 & 9 & 1.8\end{array}$

How many of the DVDs did you watch?

All 3 of them 80

$80-11$

94

14.5 
Table 3 Self-reported Participation of evaluation cohort participants in the educational intervention components. (6 Months N=1354, 12 Months $N=1275)$ (Continued)

\begin{tabular}{|c|c|c|c|c|}
\hline Two of them & 101 & 14.6 & 104 & 16.0 \\
\hline One of them & 129 & 18.7 & 116 & 17.9 \\
\hline None of them & 272 & 39.4 & 250 & 38.5 \\
\hline I didn't get any DVDs & 109 & 15.8 & 85 & 13.1 \\
\hline \multicolumn{5}{|c|}{ How helpful were the DVDs that you watched? } \\
\hline Very helpful & 210 & 67.7 & 234 & 75.0 \\
\hline Somewhat helpful & 61 & 19.7 & 44 & 14.1 \\
\hline A little helpful & 34 & 11.0 & 32 & 10.3 \\
\hline Not at all helpful & 5 & 1.6 & 2 & 0.6 \\
\hline \multicolumn{5}{|c|}{ Did you attend any of the taste-testing? } \\
\hline Yes & 181 & 26.3 & 228 & 35.0 \\
\hline No & 508 & 73.7 & 424 & 65.0 \\
\hline \multicolumn{5}{|c|}{ How much did the taste-testing event affect what you bought at the market? } \\
\hline A lot & 60 & 33.3 & 81 & 35.5 \\
\hline A little & 60 & 33.3 & 71 & 31.1 \\
\hline Some & 28 & 15.6 & 32 & 14.0 \\
\hline Not at all & 32 & 17.8 & 44 & 19.3 \\
\hline \multicolumn{5}{|c|}{ Did anyone else in your household use any of the LW educational materials? } \\
\hline Yes & 132 & 26.0 & 165 & 32.8 \\
\hline No & 375 & 74.0 & 338 & 67.2 \\
\hline
\end{tabular}

intake by 0.65 cups with the control group decreasing intake by 0.07 cups, $p=.0111$. This change was driven more by increases in vegetable intake $(p<.008)$ than increases in fruit intake $(p=0.2)$. In the family sites, we did not observe any significant differences in $F \& V$ change over time by experimental group.

\section{Dose response analysis}

To better understand the dose response effect of specific intervention components, use of each component by intervention site participants was examined in relation to F\&V intake (Table 6). Greater use of the markets was associated with greater change in intake of $F \& V$

Table 4 Daily Fruit and Vegetable Intake of cups/day at Baseline and 12-month follow-up (Baseline N=1597, 12 Months N=1275)

\begin{tabular}{|c|c|c|c|c|}
\hline Outcome measurement & & Baseline Mean (SE) & 12 Month FU Mean (SE) & $p$-value (group $\times$ time) \\
\hline \multirow[t]{3}{*}{ Fruit (no juice) } & Intervention & $1.23(0.04)$ & $1.39(0.06)$ & \\
\hline & Control & $1.35(0.06)$ & $1.31(0.07)$ & \\
\hline & differences & $-0.12(0.07)$ & $0.08(0.09)$ & 0.056 \\
\hline \multirow[t]{3}{*}{ Vegetable (no fries) } & Intervention & $2.04(0.09)$ & $2.32(0.15)$ & \\
\hline & Control & $2.13(0.12)$ & $2.10(0.06)$ & \\
\hline & differences & $-0.09(0.15)$ & $0.22(0.16)$ & $0.01^{*}$ \\
\hline \multirow[t]{3}{*}{ FV combined } & Intervention & $3.25(0.10)$ & $3.69(0.20)$ & \\
\hline & Control & $3.49(0.17)$ & $3.41(0.09)$ & \\
\hline & differences & $-0.24(0.19)^{\mathrm{a}}$ & $0.28(0.22)$ & $0.015^{*}$ \\
\hline \multirow[t]{3}{*}{ FVHQ } & Intervention & $3.30(0.07)$ & $3.54(0.06)$ & \\
\hline & Control & $3.31(0.07)$ & $3.45(0.06)$ & \\
\hline & differences & $-0.01(0.10)$ & $0.09(0.08)$ & $0.01^{*}$ \\
\hline
\end{tabular}

All models were adjusted for age

*indicates statistical significance $(p<0.05)$

\#6 month data included in models but not shown in table 
Table 5 Daily Fruit and Vegetable Intake of cups/day at Baseline and 12-month follow-up by site type up (Baseline $\mathrm{N}=1597$, 12 Months $N=1275)^{\#}$

\begin{tabular}{|c|c|c|c|c|}
\hline \multicolumn{2}{|l|}{ Outcome measurement } & Baseline Mean (SE) & 12 Month FU Mean (SE) & $p$-value (group $\times$ time) ${ }^{\#}$ \\
\hline \multicolumn{5}{|c|}{ Elderly/Disabled Housing Sites Only } \\
\hline \multirow[t]{3}{*}{ Fruit (no juice) } & Intervention & $1.27(0.05)$ & $1.45(0.09)$ & \\
\hline & Control & $1.34(0.09)$ & $1.36(0.07)$ & \\
\hline & differences & $-0.13(0.10)$ & $0.09(0.12)$ & 0.20 \\
\hline \multirow[t]{3}{*}{ Vegetable (no fries) } & Intervention & $2.17(0.11)$ & $2.58(0.17)$ & \\
\hline & Control & $2.26(0.17)$ & $2.17(0.08)$ & \\
\hline & differences & $-0.09(0.20)$ & $0.41(0.19)$ & $0.008^{*}$ \\
\hline \multirow[t]{3}{*}{ F\&V combined } & Intervention & $3.37(0.12)$ & $4.02(0.27)$ & \\
\hline & Control & $3.61(0.26)$ & $3.54(0.13)$ & \\
\hline & differences & $-0.25(0.28)$ & $0.49(0.30)$ & $0.011^{*}$ \\
\hline \multicolumn{5}{|l|}{ Family Housing Sites Only } \\
\hline \multirow[t]{3}{*}{ Fruit (no juice) } & Intervention & $1.26(0.03)$ & $1.29(0.02)$ & \\
\hline & Control & $1.36(0.05)$ & $1.23(0.12)$ & \\
\hline & differences & $-0.10(0.06)$ & $0.06(0.13)$ & 0.25 \\
\hline \multirow[t]{3}{*}{ Vegetable (no fries) } & Intervention & $1.85(0.09)$ & $1.94(0.10)$ & \\
\hline & Control & $1.97(0.07)$ & $2.02(0.05)$ & \\
\hline & differences & $-0.12(0.11)$ & $-0.08(0.11)$ & 0.78 \\
\hline \multirow[t]{3}{*}{ F\&V combined } & Intervention & $3.08(0.13)$ & $3.21(0.07)$ & \\
\hline & Control & $3.34(0.09)$ & $3.26(0.10)$ & \\
\hline & differences & $-0.26(0.16)$ & $-0.06(0.12)$ & 0.35 \\
\hline
\end{tabular}

All models were adjusted for age

*indicates statistical significance $(p<0.05)$

\#6 month data included in models but not shown in table

at 12 months. There was a clear dose response effect with $F \& V$ intake change increasing with each level of increased market attendance from no markets to all of the markets $(p<.05)$. Individuals who reported attending all or most of the markets increased F\&V intake by 2.1 cups and 0.86 cups, respectively compared with less than half cup increases for lower levels of market attendance.

Reading of newsletters or attending any campaign events was not associated with any change in F\&V consumption. However, watching of the DVDs, even one compared with none at all, was associated with a 0.47 cup increase in consumption of vegetables $(p<.005)$ and 0.69 cup increase in F\&V combined $(p<.02)$. In addition, those who tried most or all of the recipes had higher increases in vegetable and $F \& V$ intake than those who used few or no recipes ( $p=02$ and 0.03 , respectively) and those who attended at least one taste test had higher increases in fruit, vegetable and $F \& V$ intake than those who attended no taste tests $(P=0.01,0.03$ and 0.004 , respectively).

Responses to the open-ended questions revealed additional information about participants' reactions to LWVB. When intervention group participants reported what they liked most about LWVB, the most common responses were related to the information provided (e.g. "it educates you, makes you change your eating habits"). The top specific categories were related to convenience/accessibility (e.g. "Didn't have to lug 20 pounds from the grocery store"), recipes, education about F\&V (e.g. "the information on what $F \& V$ you should be eating"), and the quality of the $F \& V$ (e.g. "very fresh"). When asked what they had learned from LWVB, participants mentioned the importance of eating more F\&V. They also talked about how to eat healthier in general and how to prepare F\&V (including using new recipes). They also discussed the importance of eating a variety of F\&V. When asked how the LWVB project could be improved, most respondents said that it didn't need improvement. Others cited lower prices, more education and recipes, to continue to bring LWVB to them, and to offer different market times. Additionally, participants suggested that we improve our reach to others in the community with more and better advertising.

\section{Discussion}

'Live Well, Viva Bien' (LWVB) is the first cluster, randomized controlled trial to demonstrate the efficacy 
Table 6 Change in F\&V intake of cups/day at each level of market attendance and participation in educational intervention components at 12 months ( $N=653)$

\begin{tabular}{|c|c|c|c|c|c|c|}
\hline \multicolumn{7}{|l|}{ Markets Attended } \\
\hline Change In & $\begin{array}{l}\text { All } \\
\text { Mean (Std. Dev) (n) }\end{array}$ & $\begin{array}{l}\text { Most } \\
\text { Mean (Std. Dev) (n) }\end{array}$ & $\begin{array}{l}\text { Some } \\
\text { Mean (Std. Dev) (n) }\end{array}$ & $\begin{array}{l}\text { Few } \\
\text { Mean (Std. Dev) (n) }\end{array}$ & $\begin{array}{l}\text { None } \\
\text { Mean (Std. Dev) (n) }\end{array}$ & $\begin{array}{l}P \text {-value } \\
\text { (2 sided) }\end{array}$ \\
\hline Fruit (no juice) & $0.96(1.98)(26)$ & $0.52(1.52)(23)$ & $0.05(1.64)(91)$ & $0.14(1.50)(400)$ & $0.13(1.48)(108)$ & 0.07 \\
\hline Vegetables (no fries) & $1.08(2.55)(23)$ & $0.32(2.55)(22)$ & $0.34(1.93)(86)$ & $0.20(1.99)(382)$ & $0.12(1.71)(99)$ & 0.30 \\
\hline $\begin{array}{l}\text { Fruit+Veg (no fries, } \\
\text { no juice) }\end{array}$ & 2.08 (3.09) (23) & $0.86(3.30)(22)$ & $0.38(2.92)(86)$ & $0.34(2.69)(381)$ & $0.24(2.56)(99)$ & $0.046^{*}$ \\
\hline \multicolumn{7}{|l|}{ Recipes Tried } \\
\hline \multicolumn{2}{|l|}{ Variable } & $\begin{array}{l}\text { All Mean } \\
\text { (Std. Dev) (n) }\end{array}$ & $\begin{array}{l}\text { Most Mean } \\
(\text { Std. Dev) (n) }\end{array}$ & $\begin{array}{l}\text { Some Mean } \\
\text { (Std. Dev) (n) }\end{array}$ & $\begin{array}{l}\text { None /I didn't get } \\
\text { recipes Mean } \\
\text { (Std. Dev) (n) }\end{array}$ & $P$-value ( 2 sided) \\
\hline \multicolumn{2}{|l|}{ Fruit (no juice) } & $0.33(1.75)(69)$ & $0.22(1.61)(105)$ & $0.13(1.54)(306)$ & $0.14(1.45)(166)$ & 0.79 \\
\hline \multicolumn{2}{|l|}{ Vegetables (no fries) } & $0.49(3.13)(64)$ & $0.70(2.01)(98)$ & $0.19(1.85)(294)$ & $-0.05(1.54)(155)$ & $0.02^{*}$ \\
\hline \multicolumn{2}{|c|}{ Fruit+Veg (no fries, no juice) } & $0.89(4.00)(64)$ & $0.98(2.50)(98)$ & $0.30(2.71)(294)$ & $0.08(2.28)(154)$ & $0.03^{*}$ \\
\hline \multicolumn{7}{|l|}{ Newsletter } \\
\hline & \multicolumn{3}{|l|}{ Read at least Half } & \multicolumn{2}{|c|}{ Did not read at least half } & $P$-value ( 2 sided) \\
\hline Fruit (no juice) & \multicolumn{3}{|l|}{$0.21(1.66)(287)$} & \multicolumn{2}{|l|}{$0.14(1.48)(333)$} & 0.57 \\
\hline Vegetables (no fries) & \multicolumn{3}{|l|}{$0.24(2.19)(274)$} & \multicolumn{2}{|l|}{$0.22(1.83)(314)$} & 0.93 \\
\hline $\begin{array}{l}\text { Fruit+Veg (no fries, } \\
\text { no juice) }\end{array}$ & \multicolumn{3}{|l|}{$0.43(3.02)(274)$} & \multicolumn{2}{|l|}{$0.38(2.55)(313)$} & 0.84 \\
\hline \multicolumn{7}{|l|}{ DVDs } \\
\hline & \multicolumn{3}{|c|}{ Watched at least one DVD } & \multicolumn{2}{|l|}{ Watched no DVDs } & $P$-value ( 2 sided) \\
\hline Fruit (no juice) & \multicolumn{3}{|l|}{$0.19(1.57)(313)$} & \multicolumn{2}{|l|}{$0.15(1.53)(332)$} & 0.71 \\
\hline Vegetables (no fries) & \multicolumn{3}{|l|}{$0.47(2.20)(302)$} & \multicolumn{2}{|l|}{$0.02(1.74)(308)$} & $0.005^{*}$ \\
\hline $\begin{array}{l}\text { Fruit+Veg (no fries, } \\
\text { no juice) }\end{array}$ & \multicolumn{3}{|l|}{$0.69(2.89)(302)$} & \multicolumn{2}{|l|}{$0.15(2.60)(307)$} & $0.015^{*}$ \\
\hline \multicolumn{7}{|l|}{ Taste Tests } \\
\hline & \multicolumn{3}{|c|}{ Attended any taste tests } & \multicolumn{2}{|c|}{ Attended no taste tests } & $P$-value ( 2 sided) \\
\hline Fruit (no juice) & \multicolumn{3}{|l|}{$0.38(1.71)(228)$} & \multicolumn{2}{|l|}{$0.06(1.44)(420)$} & $0.012^{*}$ \\
\hline Vegetables (no fries) & \multicolumn{3}{|l|}{$0.47(2.26)(216)$} & \multicolumn{2}{|l|}{$0.11(1.82)(396)$} & $0.032^{*}$ \\
\hline $\begin{array}{l}\text { Fruit+Veg (no fries, } \\
\text { no juice) }\end{array}$ & $0.84(3.18)(216)$ & & & $0.18(2.46)(395)$ & & $0.004^{*}$ \\
\hline Campaign Participation & & & & & & \\
\hline & Attended any of the & campaign events & & Attended no campa & ign events & $P$-value ( 2 sided) \\
\hline Fruit (no juice) & $0.28(1.62)(244)$ & & & $0.09(1.49)(393)$ & & 0.13 \\
\hline Vegetables (no fries) & $0.23(2.16)(231)$ & & & $0.20(1.76)(372)$ & & 0.84 \\
\hline $\begin{array}{l}\text { Fruit+Veg (no fries, } \\
\text { no juice) }\end{array}$ & $0.51(2.94)(231)$ & & & $0.30(2.50)(371)$ & & 0.34 \\
\hline
\end{tabular}

${ }^{*}$ indicates statistical significance $(p<0.05)$

of year-round F\&V markets at improving F\&V intake for low-income adults. Overall, the LWVB intervention increased $F \& V$ intake more than the control group by approximately 0.52 cups and there was a dose-response effect demonstrating that greater market attendance resulted in greater $F \& V$ intake. Non-experimental studies have shown that seasonal farmers' markets selling local produce can increase
F\&V intake of participants; but these studies used cross-sectional or one-group, repeated-measures designs [33-37], not randomized controlled trials. Moreover, these studies only measured F\&V change of market participants. Several other studies have examined the efficacy of educational programs and/or monetary vouchers for F\&V at farmer's markets; but did not study the efficacy of the markets themselves [38, 39]. 
The results of the LWVB study provide strong evidence in support of the hundreds of mobile F\&V markets around the country, which may facilitate procurement of funding that requires an evidence-base. For example, this study's demonstration that mobile markets can increase F\&V intake may allow such markets to be eligible for community benefit funds from local nonprofit hospitals that seek federal tax exempt status [40-43]. As of December 2014, federal rules allowed such hospitals to consider funding programs that “...prevent illness, to ensure adequate nutrition, or to address social, behavioral, and environmental factors that influence health in the community" [42] as long as the programs they fund are evidence-based.

The LVWB study found that the elderly/disabled housing sites had greater changes in F\&V intake in comparison to the family sites. This finding is likely related to higher involvement in the markets and educational interventions by the elderly/disabled site residents compared to the family site residents, and that elderly individuals, in general, are likely to be more health conscious than younger individuals. At the elderly/disabled sites, the markets were held indoors so participants only needed to take the elevator downstairs to shop, while at family sites, the markets were held outside or in non-adjacent buildings, which required residents to leave their apartments and walk down the street to shop. Another explanation may pertain to elderly/disabled subpopulations being particularly vulnerable to barriers in food access. In other words, they may be hypersensitive to food environment changes made in close proximity to their homes because of physical limitations or inability to drive to a grocery store [44]. Future studies should consider how to maximize such programs for elderly and disabled individuals as well as how to create programs that might be more attractive to younger families.

The dose response data also indicate that higher market participation was associated with greater increases in F\&V intake. This is an important finding, which highlights the significance of regular market attendance and reach. A systematic review by Freedman and collaborators identified several factors influencing farmer's market use that are likely applicable to mobile market participation, including economic facilitators/barriers, service delivery, spatial/temporal, social, and personal factors [45]. More research is needed to determine how to modify future markets to encourage increased participation and greater reach. We conducted group concept mapping to examine factors that may have affected FTY market participation and will publish the results in a subsequent publication.

The results of LWVB also inform the field about educational programming in conjunction with $F \& V$ market programs. LWVB process evaluation data indicate that participation in most of the educational intervention components (campaigns, newsletters, DVDs, recipes and taste tests) was not particularly high. Of these components, watching the DVDs, attending taste-testing events and using recipes were associated with increased F\&V intake. The LWVB DVDs mostly featured cooking segments, which appeared to be of interest to study participants as well as the recipes corresponding to these cooking segments. These findings provide important implications for future interventions especially with low-income, less literate audiences. An audiovisual intervention may be the best approach for reaching such groups. Future interventions should study how to repackage such interventions to reach more F\&V market participants. For example, should they be distributed as DVDs at markets or would it be more effective to send video clips and/or recipes through email or text links? Would it be helpful to provide scan codes at pointof-purchase that would then send links to videos and/or recipes via email or text? The reach, feasibility, acceptability and efficacy of such interventions could be examined in future studies.

Alternatively, in order to increase participation in the educational components, future interventions might consider embedding the nutrition education component as a requirement for participants to receive discount produce or financial benefits. This strategy was employed in the Health Bucks study, a randomized control trial, which found that coupling an hour-long, group nutrition education program with a small, economic incentive (\$6 coupon) was effective at increasing F\&V purchasing and consumption among overweight patients with diabetes [46].

Taste-testing events may also be important at mobile markets as a draw to increase attendance at the markets and to provide opportunities for consumers to try $F \& V$ and receive recipes for preparing them in new and different ways. Cost-efficient ways to implement taste-testing events at mobile markets could include working with SNAP-Ed, the Expanded Food and Nutrition Education Program (EFNEP) or local culinary schools that could provide such events as a community service.

Discount, mobile produce markets like those in the LWVB study have the opportunity to not only increase F\&V consumption; but also to increase food security because the $F \& V$ prices are lower than supermarket prices. However, while LWVB markets had lower prices than supermarkets, they still appeared to be too high for participants to purchase large amounts of F\&V. Sales averaged only $\$ 8.55$ per person and some participants reported that FTY market prices were still too high. As this was a research efficacy study it did not focus on, nor did it evaluate the cost or profitability of the markets. The LWVB markets required extra staff and a POS 
system for evaluation purposes and thus could not estimate costs for markets in a non-research situation. Most mobile F\&V markets operating in food deserts or low income neighborhoods are non-profits that require donations and/or grant funds to operate [47]. Future studies should look at costs and cost-effectiveness of mobile F\&V markets and market plus education interventions like LWVB and determine ways in which mobile markets could be self-sustaining. Potential approaches to reducing per market cost could be using housing site residents or other volunteers as market staff, or having students work at the markets for their community service requirements. Profitability could possibly be increased by increasing reach and/or by selling other items at the mobile market besides produce.

Financial incentives may be important for low-income resident participation in farmers' markets and mobile F\&V markets. A study by Freedman and colleagues points to the effectiveness of monetary incentives and SNAP-EBT and WIC acceptance at increasing the use of farmers' markets among WIC recipients [48]. While LWVB markets did accept SNAP-EBT, they could not accept WIC because FTY was not an approved WIC vendor or a "farmers' market" selling only local F\&V. The WIC Farmers' Market Nutrition Program (FMNP) [49] was established in 1992 to provide fresh, unprepared, locally grown F\&V to WIC participants, and to expand the awareness, use of, and sales at farmers' markets. Women, infants (over 4 months old) and children who have been certified to receive WIC program benefits or who are on a waiting list for WIC certification are eligible to participate in the WIC FMNP. In RI, the farmers' market vouchers are valid for one season, from June through October. Generally, such vouchers have not been fully utilized with redemption rates in RI averaging less than $40 \%$ (personal communication, RI Department of Health). Barriers have included high F\&V prices, limited seasonal availability and inconvenient locations of some farmers' markets. If it were possible for year-round mobile markets, like FTY, that sell F\&V from local farms as well as culturally desired, non-local produce, to accept WIC, low-income families could have year-round access to affordable, fresh produce at convenient locations. Allowing WIC FMNP coupons to be accepted at mobile markets as well as at farmers' markets would enable more coupons to be redeemed, thereby benefitting local farmers as well as low-income families.

Financial incentives such as those offered by the United States Department of Agriculture's Food Insecurity Nutrition Incentive (FINI) program may also help to increase the fresh F\&V purchases of low-income families. The FINI program enables SNAP recipients to receive coupons that increase the monetary value of their SNAP dollars for the F\&V they buy at produce markets [50, 51]. For example some programs provide a coupon that doubles the value of SNAP benefits, e.g. buy $\$ 15$ of $F \& V$ and get a matching $\$ 15$ coupon that can be used to buy more $F \& V$; while other programs provide a coupon worth $2 / 5$ or $3 / 5$ of the amount of F\&V purchased with SNAP benefits. Ongoing studies are evaluating the effectiveness of these programs; however, further research on the relationship between pricing, financial incentives and F\&V intake in low-income families is needed.

Moreover, in LWVB we found that market participation dropped off substantially after the first 2 weeks of the month when residents' SNAP benefits ran out. This phenomenon has been shown to be an issue locally and nationally $[52,53]$ and has been related to increased food insecurity, increased hospital admissions, lower student test scores and increased disciplinary events among school-aged children in later weeks of the month [54]. Future research should look at ways to circumvent this problem, for example allowing FINI coupons to be used by SNAP recipients to purchase $F \& V$ at produce markets even after their EBT benefits have run out for the month or providing SNAP-EBT benefits more frequently, e.g., weekly or biweekly, rather than just once per month.

Another approach that could be used to decrease the cost and increase the purchase and consumption of F\&V would be to have medical professionals write prescriptions for F\&V that would then be covered by insurance and redeemed at the markets. This approach has been used and tested by Wholesome Wave in various sites across the county. They have also published a detailed toolkit for other organizations interested in implementing such an approach [55]. Further, recent empirical studies of $F \& V$ prescription programs indicate positive impacts on healthy food access, food insecurity, perceived health, hemoglobin levels among diabetes as well as BMI status [56-59].

Despite the positive results of the LWVB intervention on F\&V intake, several study limitations need to be noted. The study sample included mostly (73\%) women with few men participating. The preponderance of female participants can be attributed mostly to the overall higher percentage of women living in the housing complexes, particularly in the family sites. In addition, one of the evaluation cohort eligibility requirements was that participants needed to shop for household food at least half of the time. While men and woman are sharing food shopping responsibilities more than in the past, women are still more likely to have primary responsibility for food shopping [60]. F\&V intake was measured via self-report (although validated tools were used and a control group allowed 
for comparisons between exposures with similar measures). Market attendance at the FTY markets was not consistently high at some of the housing sites, particularly the family sites, and participation in many of the educational intervention components was also relatively low. The evaluation was conducted on all participants in the evaluation cohort, not just on intervention participants; so the overall analysis is conservative with respect to the effect of the intervention. However, the dose response analysis demonstrates the effectiveness of the intervention on those who participated. The LWVB study could not completely differentiate the effect of the market intervention vs. the educational intervention, so future studies should be designed to separate these effects. Strengths of the study included the cluster, randomized controlled trial study design, the formative research used to design the interventions, the community collaborations, diversity of the study population, the use of validated measures, the extensive process evaluation and dose response evaluation. Additionally, the large number and diversity of housing sites and participants allows for better generalizability of the results.

\section{Conclusions}

The findings from the LWVB study make a substantial contribution to the field by providing important scientific evidence regarding the efficacy of mobile produce market programs. Further, our results more broadly support investment in environmental changes to alleviate disparities in F\&V consumption and diet-related health inequities. Now that we know that mobile market programs can be effective at increasing $F \& V$ intake of low-income consumers, future implementation and dissemination research is needed regarding how to increase reach and participation in such programs, as well as how to deliver educational programming in effective and feasible ways. Other adaptations that might be considered to improve future mobile markets include: expanding market inventory to include often-requested staple, non-produce food items; working with state WIC programs to allow WIC coupon redemption at mobile markets; finding better locations for reaching low-income families; partnering with community stakeholders bringing mobile events to underserved neighborhoods, e.g., blood drives, SNAP enrollment events, health fairs, summer food programs, etc.; including incentive programs, e.g., "double up" SNAP benefits; and engaging students and/or other volunteers as market/education staff. Future studies should measure not only F\&V intake, but also the impact of F\&V market programs on total diet, food insecurity and/or health outcomes.

\section{Appendix}

Table 7 Intraclass Correlation Coefficients (ICC) from 3-level hierarchical model (Baseline $N=1597,6$ Months $N=1354$, 12 Months $N=1275$ )

\begin{tabular}{lll}
\hline & $\begin{array}{l}\text { Across time within } \\
\text { residents of the } \\
\text { same site }\end{array}$ & $\begin{array}{l}\text { Between two } \\
\text { residents of the } \\
\text { same site }\end{array}$ \\
\hline Fruit & 0.370 & 0.003 \\
Vegetables & 0.368 & 0.018 \\
Fruit and Vegetables & 0.423 & 0.014 \\
FVHQ & 0.643 & 0.053 \\
\hline
\end{tabular}

\section{Abbreviations}

DVD: Digital video disk; EBT: Electronic benefits transfer; F\&V: Fruits and vegetables; FTY: Fresh to you; LWVB: Live Well, Viva Bien; NCl: National Cancer Institute; POS: Point-of-sale; SCT: Social cognitive theory; SES: Socioeconomic status; SNAP: Supplemental nutrition assistance program

\section{Acknowledgements}

The authors would like to acknowledge the following individuals for their help with the study and/or with the preparation of this manuscript: Hilda Castillo, Elizabeth Langevin, Robert Catanzaro, Reese Middler, Rhadames Castillo, Lizette Muriel, and Robin Scheer.

\section{Funding}

This research was funded by the National Cancer Institute, Grant \#R01CA134903. The funding body was not involved in the design of the study, collection, analysis, and interpretation of data, nor in writing the manuscript.

\section{Availability of data and materials}

Data and intervention materials are available upon request to the corresponding author.

\section{Authors' contributions}

KG conceived of the study, was the PI of the study, took the lead in its design and coordination, led the writing of the manuscript; GG also conceived of the study, served as Program Director running the day-to-day study, led the writing on background and intervention sections of the paper and edited the entire paper; PR was the evaluation coordinator of the project, led the writing about statistics and measures and edited the entire paper; ADK assisted with the literature review, and edited the entire paper; LD was the Data Manager for the Project, assisted with writing the methods section, created the study flow chart, and edited the entire paper; JM was the statistical programmer and ran the statistical analyses for the paper and assisted with the results and statistical methods sections; KCS is a post doctoral fellow working with Dr. Gans. She assisted in writing the discussion section. GP was the biostatistician for the project and guided the statistical analyses, read the entire paper and provided guidance on the statistical methods and results section; SW was a student who worked on the study and assisted with the literature review and checklists; All authors read and approved the final manuscript.

\section{Authors' information}

When the study began, KG was a fulltime faculty member at Brown University. In Fall 2014, KG became a fulltime faculty member at the University of Connecticut, but remains an adjunct faculty member at Brown University. She remained PI of the grant. When Dr. Gans changed to an Adjunct Professor status at Brown, Dr. Patricia Risica at Brown University was added as a second $\mathrm{Pl}$ on the remaining term of the grant.

\section{Ethics approval and consent to participate}

This study was originally approved by the Brown University Institutional Review Board in March 2009. Latest approval was given on March 9, 2016. All study participants provided consent to participate prior to involvement in the study. 


\section{Consent for publication}

Not applicable.

\section{Competing interests}

The authors declare that they have no competing interests.

\section{Publisher's Note}

Springer Nature remains neutral with regard to jurisdictional claims in published maps and institutional affiliations.

\section{Author details}

'Department of Human Development and Family Studies, University of Connecticut, Storrs, USA. ${ }^{2}$ University of Connecticut Intitute for Collaboration in Health, Interventions and Policy, Storrs, USA. ${ }^{3}$ Center for Health Equity Research, Brown University School of Public Health, Providence, USA. ${ }^{4}$ Deartment of Behavioral and Social Science, Brown University School of Public Health, Providence, USA. ${ }^{5}$ University of Connecticut Rudd Center for Food Policy and Obesity, Hartford, USA. ${ }^{6}$ Department of Statistical Scieces, Brown University School of Public Health, Providence, USA. ${ }^{7}$ Yale University School of Public Health, New Haven, USA.

Received: 3 March 2018 Accepted: 20 July 2018

Published online: 20 August 2018

\section{References}

1. Adebawo O, Salau B, Ezima E, et al. Fruits and vegetables moderate lipid cardiovascular risk factor in hypertensive patients. Lipids Health Dis. 2006;5:14.

2. Crowe FL, Roddam AW, Key TJ, et al. Fruit and vegetable intake and mortality from ischaemic heart disease: results from the European prospective investigation into Cancer and nutrition (EPIC)-heart study. Eur Heart J. 2011;32(10):1235-43.

3. Jeurnink SM, Buchner FL, Bueno-de-Mesquita HB, et al. Variety in vegetable and fruit consumption and the risk of gastric and esophageal cancer in the European Prospective Investigation into Cancer and Nutrition. Int J Cancer. 2012;131(6):E963-73.

4. Wang $X$, Ouyang $Y$, Liu J, et al. Fruit and vegetable consumption and mortality from all causes, cardiovascular disease, and cancer: systematic review and dose-response meta-analysis of prospective cohort studies. BMJ. 2014;349:94490.

5. Nguyen B, Bauman A, Gale J, Banks E, Kritharides L, Ding D. Fruit and vegetable consumption and all-cause mortality: evidence from a large Australian cohort study. Int J Behav Nutr Phys Act. 2016;13:9.

6. Leenders M, Sluijs I, Ros MM, et al. Fruit and vegetable consumption and mortality: European prospective investigation into cancer and nutrition. Am J Epidemiol. 2013;178(4):590-602.

7. Lim SS, Vos T, Flaxman AD, et al. A comparative risk assessment of burden of disease and injury attributable to 67 risk factors and risk factor clusters in 21 regions, 1990-2010: a systematic analysis for the Global Burden of Disease Study 2010. Lancet. 2012;380(9859):2224-60.

8. Woodside JV, Young IS, McKinley MC. Fruits and vegetables: measuring intake and encouraging increased consumption. Proc Nutr Soc. 2013; 72(2):236-45.

9. WHO/FAO J. Expert Consultation Diet, nutrition and the prevention of chronic diseases. World Health Organ Tech Rep Ser. 2006;916:1-149.

10. Moore LV, Thompson FE. Adults Meeting Fruit and Vegetable Intake Recommendations - United States, 2013. MMWR Morb Mortal Wkly Rep. 2015;64(26):709-13.

11. Prevention CfDCa. State indicator report on fruits and vegetables. May 2013 2013.

12. Kirkpatrick SI, Dodd KW, Reedy J, Krebs-Smith SM. Income and race/ethnicity are associated with adherence to food-based dietary guidance among US adults and children. J Acad Nutr Diet. 2012;112(5):624-35. e626

13. Graham DJ, Pelletier JE, Neumark-Sztainer D, Lust K, Laska MN. Perceived social-ecological factors associated with fruit and vegetable purchasing, preparation, and consumption among young adults. J Acad Nutr Diet. 2013; 113(10):1366-74.

14. Williams LK, Thornton L, Crawford D. Optimising women's diets. An examination of factors that promote healthy eating and reduce the likelihood of unhealthy eating. Appetite. 2012;59(1):41-6.
15. Nicklas TA, Jahns L, Bogle ML, et al. Barriers and facilitators for consumer adherence to the dietary guidelines for Americans: the HEALTH study. J Acad Nutr Diet. 2013;113(10):1317-31.

16. Zepeda L, Reznickova A, Lohr L. Overcoming challenges to effectiveness of mobile markets in US food deserts. Appetite. 2014;79:58-67.

17. Dibsdall L, Lambert N, Bobbin R, Frewer L. Low-income consumers' attitudes and behaviour towards access, availability and motivation to eat fruit and vegetables. Public Health Nutr. 2003;6(2):159-68.

18. Schatzer $M$, Rust $P$, Elmadfa I. Fruit and vegetable intake in Austrian adults: intake frequency, serving sizes, reasons for and barriers to consumption, and potential for increasing consumption. Public Health Nutr. 2010; 13(4):480-7.

19. Goddu AP, Roberson TS, Raffel KE, Chin MH, Peek ME. Food Rx: a communityuniversity partnership to prescribe healthy eating on the south side of Chicago. J Prev Interv Community. 2015;43(2):148-62.

20. Gans KM, Gorham G, Risica PM, et al. A multi-level intervention in subsidized housing sites to increase fruit and vegetable access and intake: Rationale, design and methods of the 'Live Well, Viva Bien' cluster randomized trial. BMC Public Health. 2016;16:521.

21. Sallis JF, Owen N. Ecological models of health behavior. In: Glanz K, Rimer BK, Lewis FM, editors. Health behavior and health education: theory, research, and practice. 3rd ed. San Francisco, CA: Jossey-Bass; 2002. p. 462-84.

22. Stokols D. Translating social ecological theory into guidelines for community health promotion. Am J Health Promot. 1996;10(4):282-98.

23. McLeroy KR, Bibeau D, Steckler A, Glanz K. An ecological perspective on health promotion programs. Health Educ Q Winter 1988;15(4):351-377.

24. Baranowski T, Perry CL, Parcel GS. How individuals, environments, and health behaviors interact: social cognitive theory. In: Glanz K, Lewis FM, Rimer BK, editors. Health behavior and health education: theory, research and practice. San Francisco, CA: Jossey-Bass; 2002. p. 246-79.

25. Bandura A. Social foundations of thought and action: a social cognitive theory. Englewood Cliffs, N.J: Prentice-Hall; 1986.

26. Bandura A. Human agency in social cognitive theory. Am Psychol. 1989; 44(9):1175-84.

27. Gorham G, Dionne L, Risica PM, et al. Effectiveness and acceptability of 'Fresh To You' - an innovative, discount fresh fruit and vegetable market program in low-income neighborhoods. Preventing chronic disease. 2014,In submission.

28. Subar AF, Thompson FE, Kipnis V, et al. Comparative validation of the Block, Willett, and National Cancer Institute food frequency questionnaires : the Eating at America's Table Study. Am J Epidemiol. 2001;154(12):1089-99.

29. Treiman K, Freimuth V, Damron D, et al. Attitudes and behaviors related to fruits and vegetables among low-income women in the WIC Program. J Nutr Educ. 1996;28:149-56.

30. Quan T, Salomon J, Nitzke S, Reicks M. Behaviors of low-income mothers related to fruit and vegetable consumption. J Am Diet Assoc. 2000;100(5): 567-70.

31. Satia-Abouta J, Patterson RE, Neuhouser ML, Elder J. Dietary acculturation: applications to nutrition research and dietetics. J Am Diet Assoc. 2002; 102(8):1105-18.

32. Little RJ, Rubin DB. Statistical analysis with missing data. New York: Wiley; 1987.

33. McCormack LA, Laska MN, Larson NI, Story M. Review of the nutritional implications of farmers' markets and community gardens: a call for evaluation and research efforts. J Am Diet Assoc. 2010;110(3):399-408.

34. Freedman DA, Choi SK, Hurley T, Anadu E, Hebert JR. A farmers' market at a federally qualified health center improves fruit and vegetable intake among low-income diabetics. Prev Med. 2013;56(5):288-92.

35. Abusabha R, Namjoshi D, Klein A. Increasing access and affordability of produce improves perceived consumption of vegetables in low-income seniors. J Am Diet Assoc. 2011;111(10):1549-55.

36. Evans $A E$, Jennings $R$, Smiley AW, et al. Introduction of farm stands in lowincome communities increases fruit and vegetable among community residents. Health Place. 2012;18(5):1137-43.

37. Pitts SBJ, Wu Q, McGuirt JT, Crawford TW, Keyserling TC, Ammerman AS Associations between access to farmers' markets and supermarkets, shopping patterns, fruit and vegetable consumption and health indicators among women of reproductive age in eastern North Carolina, USA. Public Health Nutr. 2013;16(11):1944-52.

38. Herman DR, Harrison GG, Afifi AA, Jenks E. Effect of a targeted subsidy on intake of fruits and vegetables among low-income women in the special supplemental nutrition program for women, infants, and children. Am J Public Health. 2008;98(1):98-105. 
39. Anderson JV, Bybee DI, Brown RM, et al. 5 a day fruit and vegetable intervention improves consumption in a low income population. J Am Diet Assoc. 2001; 101(2):195-202.

40. Population Health Implications of the Affordable Care Act: Workshop Summary. Washington (DC) 2014.

41. Brief 1: Partner With Nonprofit Hospitals to Maximize Community Benefit Programs' Impact on Prevention. 2013.

42. Patient Protection and Affordable Care Act (PPACA). 2010.

43. Utilization of Community Benefits to Improve Healthy Food Access in Massachusetts. https://www.wholesomewave.org/sites/default/files/network/ resources/files/Utilization-of-Community-Benefits-to-Improve-Healthy-FoodAccess-in-Massachusetts_FINAL.pdf.

44. ver Ploeg $M$, Breneman $V$, Farrigan $T$, et al. Access to Affordable and Nutritious Food: Measuring and Understanding Food Deserts and Their Consequences. In: Report to Congress United States Department of Agriculture; 2009.

45. Freedman DA, Vaudrin N, Schneider C, et al. Systematic review of factors influencing Farmers' market use overall and among low-income populations. J Acad Nutr Diet. 2016;116(7):1136-55.

46. Weinstein E, Galindo RJ, Fried M, Rucker L, Davis NJ. Impact of a focused nutrition educational intervention coupled with improved access to fresh produce on purchasing behavior and consumption of fruits and vegetables in overweight patients with diabetes mellitus. Diabetes Educ. 2014;40(1): $100-6$.

47. Hsiao B-J. Mobile produce markets: a strategy for increasing access to fruits and vegetables among low income urban residents. Masters Theses. 2016. p. 423. https://scholarworks.umass.edu/masters_theses_2/423.

48. Freedman DA, Mattison-Faye A, Alia K, Guest MA, Hebert JR. Comparing farmers' market revenue trends before and after the implementation of a monetary incentive for recipients of food assistance. Preventing chronic disease. 2014;11:E87.

49. WIC Farmers' Market Nutrition Program (FMNP). Food and Nutrition Service 2017. 2017. https://www.fns.usda.gov/fmnp/wic-farmers-market-nutritionprogram-fmnp Accessed 17 July 2017

50. Fair food network: double up food bucks a five-year success story. http:// www.fairfoodnetwork.org/wp-content/image_archive/FFN_ DoubleUpFoodBucks_5YearReport.pdf.

51. Office of Community Services, Administration of Children and Families, U.S. Department of Health and Human Services. Healthy Food Financing Initiative. https://www.acf.hhs.gov/ocs/programs/community-economicdevelopment/healthy-food-financing.

52. Badger $E$. What happens when a family runs out of food stamps Washington Post. December 9, 201, 2015

53. Saslow E. Food stamps put Rhode Island town on monthly boom-and-bust cycle. Washington Post. 2016;16:2013.

54. Executive Office of the President of the United States. Long-term Benefits of the Supplemental Nutrition Assistance Program.2015. https://obamawhitehouse. archives.gov/sites/whitehouse.gov/files/documents/SNAP_report_final_ nonembargo.pdf

55. Wholesome Wave, The fruit and vegetable prescription toolkit. 2016. https:// www.wholesomewave.org/sites/default/files/network/resources/files/TheFruit-and-Vegetable-Prescription-Program-Toolkit.pdf.

56. Bryce $R$, Guajardo C, llarraza D, et al. Participation in a farmers' market fruit and vegetable prescription program at a federally qualified health center improves hemoglobin A1C in low income uncontrolled diabetics. Prev Med Rep. 2017;7:176-9.

57. Cavanagh M, Jurkowski J, Bozlak C, Hastings J, Klein A. Veggie Rx: an outcome evaluation of a healthy food incentive programme. Public Health Nutr. 2017; 20(14):2636-41.

58. Park OH, Brown R, Medina S. Effectiveness of a Community-based Family Nutrition and Cooking Program in East Lubbock, Texas: A Pilot Study. J Nutr Educ Behav. 2017:49:7S1-32.

59. Lauck L, Gates G. Effectiveness of the fresh Rx program in food Bank clients with chronic disease. J Nutr Educ Behav. 2017:49(7):S35-6.

60. Flagg LA, Sen B, Kilgore M, Locher UL. The influence of gender, age, education and household size on meal preparation and food shopping responsibilities. Public Health Nutr. 2014;17(9):2061-70.

\section{Ready to submit your research? Choose BMC and benefit from:}

- fast, convenient online submission

- thorough peer review by experienced researchers in your field

- rapid publication on acceptance

- support for research data, including large and complex data types

- gold Open Access which fosters wider collaboration and increased citations

- maximum visibility for your research: over $100 \mathrm{M}$ website views per year

At BMC, research is always in progress.

Learn more biomedcentral.com/submissions 